GABA-GABA: Jurnal Pengabdian Masyarakat dalam bidang Pendidikan Bahasa dan Seni

Vol. 3 No. 1, Desember 2021, Hal. 115-120

e-ISSN: 2797-8494

\title{
PENGAYAAN KOSA KATA BAHASA DAERAH BERBASIS MASYARAKAT PESISIR DI KALANGAN SISWA SMA NEGERI 55 TELUK ELPAPUTIH
}

\author{
Romilda Arivina da Costa \\ Program Studi Pendidikan Bahasa dan Sastra Indonesia \\ ronaromilda70@gmail.com
}

\begin{abstract}
Abstrak
Perkembangan dan perubahan bahasa secara masif telah menyentuh teritorial tradisional termasuk di Negeri Waraka yang terletak di pesisir Teluk Elpaputih Maluku Tengah, yang masyarakatnya menuturkan bahasa Wemale atau bahasa Waraka. Hanya generasi usia lanjut yang berkomunikasi dalam bahasa tersebut. Untuk itu, diinisiasi penyuluhan kepada generasi muda tentang pentingnya bahasa daerah melalui kegiatan pengabdian kepada masyarakat (PkM) kepada para siswa di SMA Negeri 55 Teluk Elpaputih. Metode yang digunakan adalah metode ceramah singkat disertai tanyajawab, diskusi dan mendata kosakata, serta permainan acak pasangan kartu. Hasilnya memperlihatkan bahwa kosakata bahasa daerah yang dimiliki para siswa memang sangat minim karena transmisi antara orang tua kepada anak terhambat. Namun, potensi para siswa cukup besar untuk mulai men-input kosakata sehari-hari, dan dibiasakan melalui kalimat-kalimat sederhana dari dalam keluarga. Dengan demikian, bahasa daerah memang harus diprioritaskan di rumah.
\end{abstract}

Kata kunci: pengayaan, kosakata, bahasa daerah, strategi, keluarga

\begin{abstract}
Massive language developments and changes have touched traditional territories, including in the Waraka State located on the coast of Elpaputih Bay, Central Maluku, where the people speak the Wemale language or the Waraka language. Only the older generation communicates in this language. For this reason, counseling was initiated to the younger generation about the importance of regional languages through community service activities (PkM) to students at SMA Negeri 55 Teluk Elpaputih. The method used is a short lecture method with questions and answers, discussion and vocabulary collection, as well as a random game of card pairs. The results show that the local language vocabulary owned by the students is indeed very minimal because the transmission between parents to children is hampered. However, the potential of the students is big enough to start inputting everyday vocabulary, and get used to it through simple sentences from within the family. Thus, regional languages should be prioritized at home.
\end{abstract}

Keywords: enrichment, vocabulary, regional language, strategy, family

\section{PENDAHULUAN}

Dalam kehidupan masyarakat penutur bahasa daerah telah terjadi berbagai perubahan sebagai akibat perkembangan dunia yang semakin pesat. Perkembangan iptek, khususnya teknologi informasi yang mampu menembus ruang dan waktu, telah mempengaruhi perilaku masyarakat dalam bertindak dan berbahasa, terlebih di kalangan generasi muda. Dengan fakta bahwa berbagai kata dan istilah yang digunakan dalam iptek tidak tersedia dalam bahasa daerah, mau tidak mau kosakata dalam pergaulan atau percakapan di kalangan masyarakat bahasa daerah masa kini masa kini lebih diwarnai 
oleh perilaku keilmuan dan kemajuan teknologi, seperti kata globalisasi, industri, komputer, internet, ataupun media sosial.

Ahmed (dalam Subandi, 2011: 250) dengan tajam menyatakan bahwa "televisi' merupakan siasat pemutusan hubungan yang radikal dengan masa lalu. Generasi muda secara perlahan digiring agar terintegrasi dengan kosakata dan konsep-konsep yang didengar dan ditonton dari iklan atau tayangan acara-acara yang begitu beragam. Dengan sifatnya yang audiovisual, TV memiliki keunggulan dalam hal menampilkan tayangan gambar bergerak (motion picture) sehingga khalayak pemirsa lebih terlibat secara emosional dibandingkan mereka melihat gambar mati seperti yang terpampang pada koran atau majalah.

Perkembangan dan perubahan bahasa bukan saja menyentuh wilayah perkotaan, melainkan secara masif pun telah menyentuh teritorial tradisional perdesaan sebagaimana yang terjadi di Maluku, termasuk di Negeri Waraka yang terletak di pesisir Teluk Elpaputih. Kenyataannya, masyarakat yang menggunakan bahasa daerah cuma generasi usia lanjut ( $>70$ tahun). "Serangan paling gencar" terjadi pada generasi muda, yakni menyangkut kemilikan kosakata mereka. Jika bersandar pada salah satu pengertian kosakata sebagai kata-kata yang dikuasai oleh seseorang/sekelompok orang dari lingkungan yang sama (Chaer, 2007: 6-7), cerita tentang penguasaan kosakata generasi muda perlu ditunda, mengingat kemilikannya yang tidak seberapa.

Berdasarkan Atlas Bahasa Tanah di Maluku wilayah Teluk Elpaputih tergolong dalam wilayah yang menggunakan bahasa Wemale Selatan (Taber, 1996: 52). Negeri Waraka yang terletak di Kecamatan Teluk Elpaputih adalah sebuah negeri yang penduduknya menggunakan bahasa Wemale Selatan, tetapi mereka menamakannya bahasa Waraka sesuai nama negeri, tempat mereka tinggal (Hasil wawancara dengan seorang tokoh adat Negeri Waraka). Secara sistemik, bahasa ini tidak berbeda dengan bahasa Wemale Utara karena memang penduduk Waraka berasal dari Kolikolea yang terletak di sebelah utara Negeri Waraka yang sekarang. Negeri lama itu berada 500 meter dari permukaan laut, dan berjarak sekitar $20 \mathrm{~km}$ dari negeri yang sekarang (Bintarti, dkk., 1977: 6). Namun, situasi kebahasaan dan kompleksitas kontak dengan bahasa-bahasa para migran-lah yang kemungkinan besar membedakannya.

Berangkat dari situasi di atas, timbul gagasan untuk memberikan penyuluhan kepada generasi muda tentang pentingnya bahasa daerah setempat dalam kehidupan komunikasi, dan strategi-strategi sederhana untuk memperkaya kosakata bahasa daerah mereka terhadap melalui kegiatan pengabdian kepada masyarakat (PkM) di SMA Negeri 55 Teluk Elpaputih pada Januari 2020.

Oleh karena berdekatan dengan Negeri Waraka maka penyuluhan lebih diarahkan kepada para siswa SMA Negeri 55 Teluk Elpaputih yang merupakan penutur bahasa Wemale atau bahasa Waraka. Akan tetapi, para siswa yang menuturkan bahasa daerah yang lain pun tidak diabaikan sebab mereka dapat ikut mengevaluasi sendiri pengalaman mereka dengan bahasa daerahnya masing-masing.

\section{METODE}

Bentuk pengabdian yang dilakukan adalah memberikan penyuluhan mengenai upaya pengayaan kosakata. Metode yang digunakan dalam penyuluhan adalah metode ceramah singkat yang disertai tanya-jawab, diskusi dan mendata kosakata, serta permainan acak pasangan kartu. Melalui ceramah singkat, digambarkan tentang kekayaan budaya dan bahasa di Maluku yang menduduki tempat kedua setelah Papua, peran penting bahasa daerah dalam kehidupan masyarakat, termasuk masyarakat yang berkecimpung dalam dunia pendidikan, dan prospek bahasa daerah yang tidak terpikirkan saat ini, tetapi akan "mengejutkan" kelak.

Tanya-jawab dilangsungkan bersamaan dengan gambaran yang diberikan dalam ceramah. Tujuannya untuk menjajaki lingkungan tempat tinggal para siswa, juga latar belakang etnis, dan ekologi linguistik pada ranah keluarga, kekerabatan, ketetanggaan, dan pertemanan. Berdasarkan informasi umum sekaligus awam itu, kebiasaan berbahasa para siswa dapat diancar.

Guna membuktikan kemilikan kosakata para siswa terkait tanya-jawab yang dilakukan, mereka dibagi dalam 5 kelompok yang terdiri atas enam orang. Setiap kelompok diberikan sehelai 
kertas dengan sebuah tabel yang terdiri atas 2 kolom (kolom bahasa Indonesia dan bahasa Waraka) dengan 40 baris yang terbagi dalam 4 bagian, menurut instruksi untuk menuliskan (a) semиa yang ada di ruтаһти; (b) sетиа binatang di sekitarmu; (c) semua yang ada di laut; (d) bilangan dari 1 s.d. 10. Para siswa diminta untuk mendiskusikan kata-kata yang mereka ketahui tentang keempat hal di atas, kemudian menuangkannya sesuai bagian-bagian pada tabel tersebut.

Puncak pelaksanaan dari penyuluhan ini adalah permainan acak pasangan kartu. Permainan ini dilakukan dengan melibatkan kelima kelompok diskusi, yakni Kelompok I s.d Kelompok V. Kesempatan bermain diberikan kepada setiap kelompok secara berurut sesuai nama kelompok. Ada 10 kata yang harus dipasangkan. Kesepuluh kata itu adalah kata-kata bilangan dari 1 s.d 10, dalam bahasa Indonesia dan bahasa Wemale. Permainan ini bertujuan untuk memotivasi para siswa agar dapat berkreasi dengan cara-cara yang sederhana, ekonomis (murah meriah), tetapi bernilai dan bermanfaat besar.

Mekanisme permainan diawali dengan 20 buah kartu yang dikocok-kocok oleh seorang guru, kemudian semua kartu yang telah dikocok itu dibuka. Tugas anggota kelompok yang digilir adalah memasangkan kartu yang berbahasa Indonesia dan berbahasa Wemale sesuai dengan urutan angkaangka yang tepat.

\section{HASIL DAN PEMBAHASAN}

Hasil diskusi dan pengisian tabel sebagaimana yang tertera di bawah ini, telah menjadi bukti yang serta-merta memperlihatkan minimnya kosakata yang dimiliki para siswa.

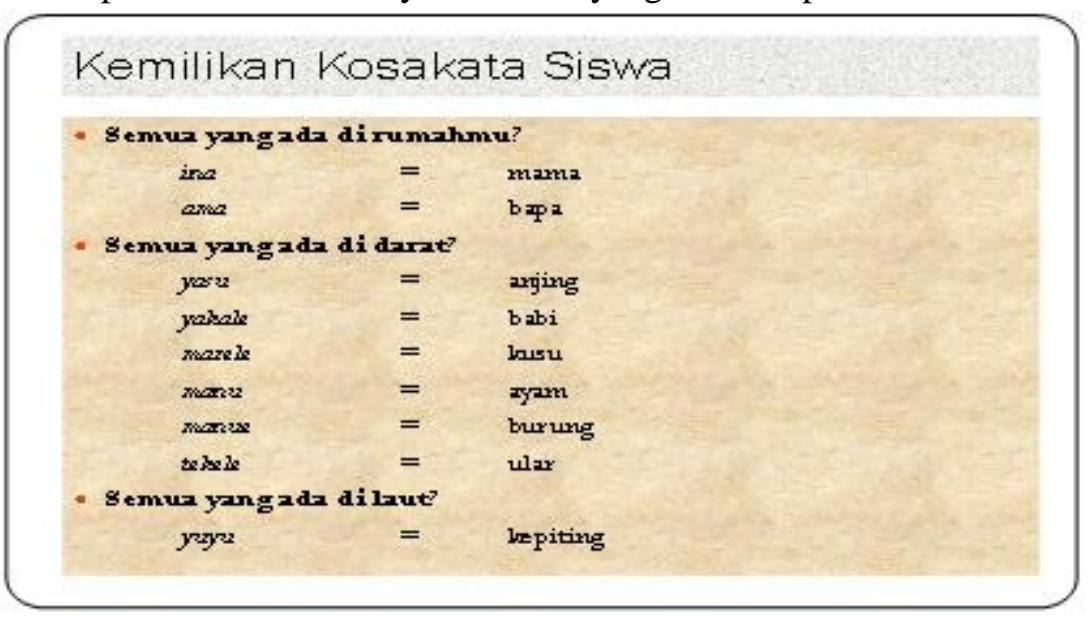

Gambar 1. Kemilikan Kosakata Siswa 


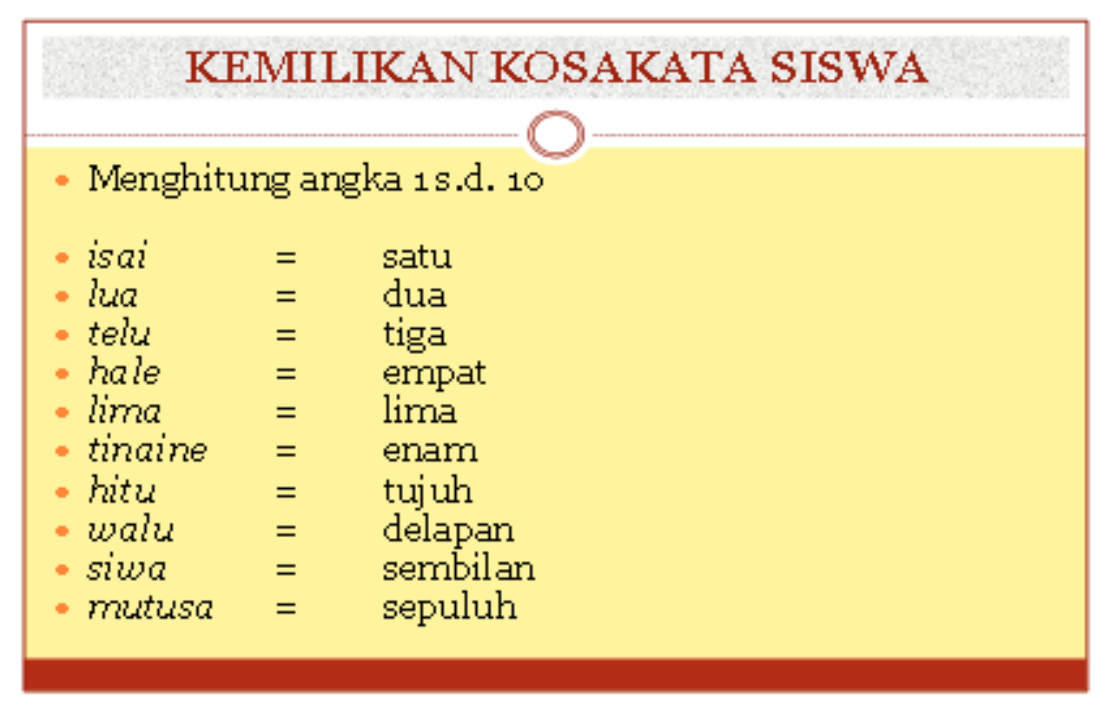

Gambar 2. Kemilikan Kosakata Siswa

Minimnya kosakata yang dimiliki para siswa berkaitan sekali dengan alasan yang mereka kemukakan. Pertama, orang tua tidak mengajarkan bahasa daerah kepada mereka. Kedua, orang tua tidak membiasakan mereka menggunakan bahasa daerah dalam komunikasi di rumah. Ketiga, jarang sekali ada teman yang menggunakan bahasa daerah. Tidak diajarkan atau dibiasakannya anak-anak menggunakan bahasa daerah karena (i) kedua orang tua pun tidak dapat berbahasa daerah; (ii) perbedaan etnis kedua orang tua; (iii) pertimbangan orang tua menyangkut adaptasi bahasa anak ketika bersekolah.

Cahyono (1995: 283-284) menjelaskan bahwa dalam penyusunan kemampuan berbahasa, anak memiliki informasi terbatas yang tersedia padanya, yaitu bahasa yang didengar dari lingkungannya. Artinya, sampai dengan usia 3 tahun anak menjadikan tuturan orang tua, dan anggota keluarga yang lain yang tinggal serumah dengannya sebagai model bahasanya (caretaker speech). Setelah itu, bahasa teman-teman sebayanya akan menjadi lebih penting baginya.

Jadi, orang tua sangat berperan penting dalam transmisi bahasa daerah. Dari beberapa penelitian sosiolinguistik yang dilakukan menyangkut penggunaan bahasa daerah di Pulau Yamdena bagian timur, dan di Kecamatan TNS di Pulau Seram, transmisi bahasa daerah dilakukan para orang tua dengan menggunakan kalimat-kalimat sederhana ketika berinteraksi di rumah. Secara linguistis, siasat ini dikenal dengan istilah tuturan pengasuh.

Berangkat dari kondisi bahasa (daerah) Waraka yang sekilas tergambar itu, tidaklah disarankan sama sekali untuk melemparkan tanggung jawab merawat bahasa daerah di sekolah, sekalipun "bertopengkan" muatan lokal. Di sekolah, tidak semua guru merupakan penutur bahasa setempat karena lebih banyak guru yang berasal atau bertugas dari daerah lain yang mungkin menuturkan bahasa yang berbeda, atau malah hanya penutur bahasa Melayu Ambon dan bahasa Indonesia. Jadi, pendidikan bahasa daerah membutuhkan keluarga dan masyarakat yang kuat, bukan masyarakat yang terlalu khawatir akan kemampuan anak di sekolah, seandainya mereka fasih berbahasa daerah.

\subsection{Prospek bagi Bahasa Daerah}

Dalam undang-undang kebahasaan dinyatakan bahwa bahasa daerah merupakan sarana komunikasi dan penyimpan keragaman pengetahuan budaya serta kearifan lokal (Lauder, 2016). Berarti, bahasa daerah memiliki fungsi yang penting untuk mewadahi komunikasi dalam teritori tradisional sehingga tidak cukup dilestarikan dan dihargai untuk kegiatan ritual dan adat istiadat semata-mata. 
Masyarakat perlu memberi ruang lebih bagi penggunaan bahasa daerah sebab ada prospek masa depan bahasa daerah yang tidak terpikirkan saat ini, tetapi yang akan "mengejutkan" kelak, yaitu (i) keterpakaiannya sebagai sandi penting dalam kondisi genting; (ii) keterpakaiannya sebagai salah satu syarat penerimaan karyawan atau pekerja di lahan-lahan industri yang memanfaatkan sumber daya alam setempat; (iii) sumbangsih konsep-konsep uniknya dalam Kamus Besar Bahasa Indonesia (KBBI).

\subsection{Aksi Peduli dan Langkah Awalnya}

Dalam konteks masa depan, setiap manusia perlu terlibat dalam sebuah civic engagement yang aktif. Untuk itu, dibutuhkan jenis kecerdasan baru yang coba dinamakan kecerdasan teritorial yang dapat dilihat dari ukuran-ukuran praktiknya dalam gagasan dan aksi yang berbasis lokal dan berjangka panjang (Amin, 2009: xvii). Dikaitkan dengan hasil permainan pasangan kartu yang cukup menggembirakan karena ada 3 kelompok yang memasangkan dengan benar, dan 2 kelompok lainnya hanya keliru dalam menempatkan dua pasangan kata terimplikasi bahwa dalam waktu singkat, mereka dapat menghafalkan kata-kata tersebut dan bekerja sama untuk memasangkannya.

Dengan demikian, para siswa dapat mulai mempraktikkan kata-kata yang mudah untuk diurut atau diantonimkan dengan anggota keluarga yang lain, ataukah dengan teman-teman di rumah. Mereka dapat memulainya dengan kata-kata seperti angka-angka, petunjuk masuk-keluar, atasbawah, kiri-kanan, depan-belakang, aktivitas pergi-pulang, naik-turun, baca-tulis, situasi siangmalam, terang-gelap, tempat-tempat seperti laut-darat, hutan-pantai, hubungan kekerabatan, seperti ayah-ibu, paman-bibi, atau kakak-adik.

Mengapa harus mulai dibiasakan? Karena kebiasaan adalah sesuatu yang setiap waktu atau selalu dilakukan. Kebiasaan tersebut akan membentuk budaya, dan budaya itu bersifat melekat. Kalau hidup berlangsung di sekitar budaya, tetapi berjarak, berarti jarang digunakan atau tidak pernah digunakan. Hal itu sama dengan sesuatu yang asing. Bahasa daerah perlu dipercakapkan sehari-hari untuk memberikan stimulus pada otak sehingga mempengaruhi ingatan seseorang. Oleh karena upaya menghafal hanya melatih seseorang untuk memperhatikan bentuk luar, tetapi dengan percakapan sehari-hari akan membuat seseorang mampu menyerap makna atau pesan atau bentuk yang lebih dalam.

Strategi sederhana yang dapat ditempuh juga, antara lain (i) mendengarkan cerita-cerita rakyat dari tete 'kakek' dan nene 'nenek'; (ii) tuliskan dalam bahasa daerah, nama benda-benda yang ada di sekeliling rumah atau di dalam rumah pada kartu-kartu yang dibuat dari karton manila; (iii) tempelkan kartu-kartu tersebut di tempat-tempat strategis di rumah sehingga mudah terbaca dan selalu dapat dibaca setiap kali berada di situ. Misalnya, di ruang belajar, ruang duduk, ruang makan, dapur, kamar tidur, juga di kamar mandi.

Dari situlah diharapkan bahasa daerah terkelola dengan baik untuk setiap generasi muda. Mengingat bahasa yang hidup itu, selain harus kokoh dalam kognisi dan kompetensi para penuturnya, dimensi produksi dan kreasi penggunaannya secara berkelanjutan harus ada dalam ranah sosial budaya pemiliknya.

\section{KESIMPULAN}

Senada dengan alasan-alasan yang dikemukakan para siswa, pendidikan bahasa daerah memang harus diprioritaskan di rumah, dan bukan di sekolah sebab tidak ada bahasa daerah yang hilang di sekolah. Dibatasinya bahasa daerah di sekolah, tidak mengindikasikan sikap sentimen terhadap bahasa daerah, tetapi merupakan sikap proporsional yang menyadari bahwa sekolah adalah ranah yang lebih 
mendahulukan bahasa nasional dengan porsi pengetahuan yang lebih luas, dan bukan hanya seputar kehidupan sosial budaya dalam teritorial tradisional.

Lebih lanjut diharapkan para siswa juga para guru bahasa dapat menginspirasi keluarganya masing-masing, juga masyarakart sekitar tempat tinggal untuk memanfaatkan waktu akhir pekan di rumah menciptakan dan menerapkan berbagai bentuk permainan yang dapat memberi kesan jangka panjang untuk mengingat sejumlah kosa kata bahasa daerah, kemudian dapat dipraktikkan dengan menggunakan kalimat-kalimat sederhana ketika berinteraksi di rumah atau dengan teman-teman ataupun para tetangga. Bentuk permainan disarankan mengingat sebagian besar masyarakat lebih banyak menghabiskan waktu di ladang atau hutan, juga di laut. Dengan begitu, mereka akan lebih menikmati belajar bahasa yang tidak harus selalu di sekolah.

\section{REFERENSI}

Amin, Basri. 2009. "Geometri Budaya dan Bahasa Masa Depan" dalam Metamorfosa Sosial dan Kepunahan Bahasa. Ternate: Lembaga Penerbitan Universitas Khairun.

Bintarti, D. D., Joyce R. Idrianingsih, Kosasih, S. A. 1977. Laporan Hasil Survai Kepurbakalaan di Daerah Maluku Tengah (Pulau Ambon, Seram, dan Sekitarnya) No. 8. Jakarta: Pusat Penelitian dan Peninggalan Nasional.

Cahyono, B. Y. 1995. Kristal-Kristal Ilmu Bahasa. Surabaya: Airlangga University Press.

Chaer, Abdul. 2007. Leksikologi dan Leksikografi Indonesia. Jakarta: Rineka Cipta.

Ibrahim, Idi S. 2011. Kritik Budaya Komunikasi. Yogyakarta: Jalasutera.

Ismail, Andar. 2011. Selamat Mewaris. Jakarta: BPK Gunung Mulia.

Lauder, Multamia. 2016. "Pencegahan Kepunahan Bahasa-Bahasa Daerah melalui Pembentukan Undang-Undang". Disampaikan dalam Seminar Nasional Sosiolinguistik dan Dialektologi, Fakultas Ilmu Pengethauan Budaya, Universitas Indonesia, Jakarta. 